\title{
ETS-related gene is a novel prognostic factor in childhood acute lymphoblastic leukemia
}

\author{
HAI-ZHAO ZHAO* ${ }^{*}$ MING JIA*, ZE-BIN LUO, XIAO-JUN XU, SI-SI LI, \\ JING-YING ZHANG, XIAO-PING GUO and YONG-MIN TANG
}

\begin{abstract}
Division of Hematology-Oncology, Children's Hospital of Zhejiang University School of Medicine, Key Laboratory of Reproductive Genetics, Zhejiang University, Ministry of Education, Hangzhou, Zhejiang 310003, P.R. China
\end{abstract}

Received June 17, 2015; Accepted October 24, 2016

DOI:10.3892/ol.2016.5397

\begin{abstract}
The ETS-related gene (ERG) has been demonstrated to be associated with overall survival in cytogenetically normal acute myeloid leukemia and acute T cell-lymphoblastic leukemia (T-ALL) in adult patients. However, there are no data available regarding the impact of ERG expression on childhood ALL. In the present study, ERG expression levels were analyzed in bone marrow samples from 119 ALL pediatric patients. ALL patients demonstrated higher ERG expression compared with the controls $(\mathrm{P}<0.0001)$. In addition, low ERG expression identified a group of patients with higher white blood cell counts $(\mathrm{P}=0.011)$, higher percentages of T-ALL immunophenotype $(\mathrm{P}=0.027)$, and higher relapse rates $(\mathrm{P}=0.009)$. Survival analyses demonstrated that low ERG expression was associated with inferior relapse-free survival (RFS) in childhood ALL $(\mathrm{P}=0.036)$ and was an independent prognostic factor in multivariable analyses for RFS. In conclusion, low ERG expression is associated with poor outcomes and may be used to serve as a molecular prognostic marker to identify patients with a high risk of relapse in childhood ALL.
\end{abstract}

\section{Introduction}

Acute lymphoblastic leukemia (ALL) is the most common malignancy in the pediatric population. Over the past decades, with the progress in risk classification schemes and frontline protocol design, the overall survival (OS) in childhood ALL has exceeded $80 \%$ with contemporary treatment regimens (1). However, 15-20\% of children with ALL have disease relapse (2). ALL is a heterogeneous disease at the cytogenetic and genetic

Correspondence to: Professor Yong-Min Tang, Division of Hematology-Oncology, Children's Hospital of Zhejiang University School of Medicine, Key Laboratory of Reproductive Genetics, Zhejiang University, Ministry of Education, 57 Zhuganxiang Road, Yan-an Street, Hangzhou, Zhejiang 310003, P.R. China

E-mail: y_m_tang@zju.edu.cn

${ }^{*}$ Contributed equally

Key words: acute lymphoblastic leukemia, childhood, ERG, prognosis, relapse levels, numerous acquired genetic abnormalities have been described in patients with ALL, including chromosomal translocations, aneuploidy, deletions, and amplifications (3). Certain genetic abnormalities, such as breakpoint cluster region/Abelson murine leukemia viral oncogene homolog 1 (BCR/ABL1) and ETS variant 6-Runt-related transcription factor 1, are well-established prognostic factors (4). However, the identification and understanding of novel genetic abnormalities remains important, in order to optimize and refine the risk-stratification strategy and individualized therapy, particularly for the high-risk and relapsed patients.

ETS transcription factors are key in cell development, differentiation, proliferation, apoptosis and tissue remodeling (5). As a member of the ETS family, the ETS-related gene (ERG) is preferentially and strongly expressed in the immature B- and T-lymphoid lineages, in addition to myeloid lineage cells (6). ERG has been demonstrated to act as a proto-oncogene that can transform NIH3T3 cells and give rise to tumors in nude mice (7). ERG gene rearrangements have been identified in Ewing sarcoma and prostate cancer $(8,9)$. Previous studies suggest that ERG overexpression is associated with inferior clinical outcome $(10,11)$ and is an independent prognostic factor in cytogenetically normal acute myeloid leukemia (AML) (12-14). Furthermore, in acute T cell-lymphoblastic leukemia (T-ALL) patients, a high level of ERG expression has been associated with poor relapse-free survival (RFS) $(15,16)$. In childhood AML, the impact of ERG expression level is somewhat controversial: Pigazzi et al (17) suggested that high ERG expression was an independent unfavorable prognostic marker for childhood myeloid leukemia, whereas the study by Hermkens et al did not find such correlation (18).

However, to the best of our knowledge, no studies have yet investigated the prognostic correlation of ERG expression in childhood ALL. The present study analyzed ERG mRNA expression levels in 119 childhood patients with newly diagnosed ALL, and aimed to validate their prognostic significance in pediatric ALL patients.

\section{Materials and methods}

Patients and treatment. The expression levels of ERG in 119 bone marrow (BM) samples from patients with newly diagnosed ALL (median age, 6 years; range, 1-14 years; 
76 males and 43 females) were retrospectively analyzed between January 2007 and December 2010 at the Children's Hospital of Zhejiang University School of Medicine (Hangzhou, China). The diagnostic criteria of ALL was based on morphology, immunology, and cytogenetics, as described previously (19). Overall, there were 91 B cell-ALL (B-ALL) patients and 28 T-ALL patients. Furthermore, 36 BM samples from children (median age, 6 years; range, 1-14 years; 23 males and 13 females) without history of malignancies were selected and served as controls. Written informed consent was obtained from the parents or guardians. All treatments were administered in accordance with the Declaration of Helsinki and approved by the ethics review board of the Children's Hospital of Zhejiang University.

Patients received treatment with the modified National Protocol of Childhood ALL in China 1997 at the hospital, which has been described in our previous study (20). Based on the modified National Cancer Institute criteria, patients were classified as low-risk (LR) group, intermediate risk (IR) group or high-risk (HR) group (20). Patients with one of the following features were considered as IR: i) Age, $>10$ years old; ii) initial white blood cell (WBC) counts $>50 \times 10^{9} / 1$ but $<100 \times 10^{9} / 1$; iii) central nervous system leukemia and/or testicular leukemia at diagnosis; iv) T lineage ALL; v) hypodiploidy ( $<45$ chromosomes). Patients with aged $<1$ year old, or initial WBC counts $\geq 100 \times 10^{9} / 1$, or with $\mathrm{t}(9 ; 22)$, t $(4 ; 11)$ or BCR/ABL1, MLL/AF4 (the fusion of the MLL gene on chromosome 11 and the AF4 gene on chromosome 4) fusion genes, or poor response to prednisone or not achieving complete remission (CR) on day 42 were considered HR. Otherwise, patients without any features as described above were assigned to the LR group.

$R N A$ isolation and reverse transcription-quantitative polymerase chain reaction ( $R T-q P C R)$. Mononuclear cells from $\mathrm{BM}$ samples were isolated by Ficoll gradient centrifugation and cryopreserved in liquid nitrogen. Total RNA was extracted using High Pure RNA Isolation Kit (Roche Diagnostics $\mathrm{GmbH}$, Mannheim, Germany) following the manufacturer's protocols. First-strand cDNA was synthesized from total RNA with reverse transcriptase and random primers, using the ReverTra Ace qPCR RT kit (Toyobo Co., Ltd., Osaka, Japan). Samples were selected based on the quality and quantity of RNA .[optical density $(\mathrm{OD})_{260} / \mathrm{OD}_{280}$ ratio, 1.8-2.0].

qPCR was performed with a 96-well optic plate on a StepOnePlus ${ }^{\text {TM }}$ Real-time PCR system (Applied Biosystems; Thermo Fisher Scientific, Inc., Waltham, MA, USA), with GAPDH as an endogenous control. Every sample was tested in triplicate. The comparative cycle threshold (CT) method was used to determine the relative expression levels of ERG to GAPDH, using the mean of $\triangle \mathrm{CT}$ from three replicates and expressed as $2^{\mu(\Delta \mathrm{CT})}(\triangle \mathrm{CT}=\mathrm{GAPDH}-\mathrm{ERG})$, as previously described (10). Each reaction mixture consisted of $2 \mu \mathrm{l}$ cDNA, $12.5 \mu \mathrm{l}$ SYBR Green PCR Master mix (Toyobo Co., Ltd.), $1 \mu \mathrm{l}$ of ERG primers $(5 \mathrm{nmol} / \mathrm{ml})$ or $1 \mu \mathrm{l}$ of GAPDH primers $(5 \mathrm{nmol} / \mathrm{ml})$ and deionized water to a total volume of $25 \mu \mathrm{l}$. The primers of ERG and GAPDH were as described in previous studies $(15,21)$, with the sequences as follows: 5'-CAC GAACGAGCGCAGAGTTA-3' for ERG1; 5'-CTGCCGCAC ATGGTCTGTAC-3' for ERG2; 5'-ATGGGGAAGGTGAAG
GTCG-3' for GAPDH1; 5'-GGGTCATTGATGGCAACA ATATC-3' for GAPDH2. PCR amplification was performed under the following conditions: First reaction, $94^{\circ} \mathrm{C}$ for $5 \mathrm{~min}$, followed by 30 cycles at $94^{\circ} \mathrm{C}$ for $30 \mathrm{sec}, 55^{\circ} \mathrm{C}$ for $30 \mathrm{sec}$ and $72^{\circ} \mathrm{C}$ for $1 \mathrm{~min}$; second reaction, $94^{\circ} \mathrm{C}$ for $5 \mathrm{~min}$, followed by 35 cycles at $94^{\circ} \mathrm{C}$ for $30 \mathrm{sec}, 58^{\circ} \mathrm{C}$ for $30 \mathrm{sec}$ and $72^{\circ} \mathrm{C}$ for $1 \mathrm{~min}$, using Taq DNA Polymerase from Toyobo (Osaka, Japan).

In addition, the Ikaros 6 (IK6) variant of Ikaros family zinc finger protein 1 gene was detected by nested PCR using primers described in a previous study (22). All PCR products were size-fractionated by electrophoresis on a $1.5 \%$ agarose gel and stained with ethidium bromide using the Image $\mathrm{Lab}^{\mathrm{TM}}$ Software of Gel Doc XR (Bio-Rad Laboratories Inc., Hercules, CA, USA).

Statistical analysis. The median value of all measurements was selected to define the low and high ERG expressing patients. Patients were classified as having high ERG if they had expression values above the median value of all patients and as low ERG if they had ERG expression values below the median value. Comparisons of baseline clinical variables across groups were conducted using the $\chi^{2}$ test and the nonparametric Mann-Whitney U test for categorical and continuous variables, respectively. Student's t-test for independent samples was selected to perform mean comparisons between distinct groups.

Estimated probabilities of RFS and OS were calculated using the Kaplan-Meier method, and the log-rank test evaluated differences between survival distributions. RFS was determined from the date of achieving CR to relapse, any mortality or last contact. OS was measured from the date of first diagnosis until the date of mortality regardless of cause, censoring for patients alive at last follow-up. The last follow-up was September 2014. Multivariable proportional hazards models were constructed for RFS and OS, using a stepwise forward selection procedure. The following covariates were included in the full model: Age ( $\leq 1$ year, $\geq 10$ years vs. $1-10$ years), WBC counts $\left(\geq 50 \times 10^{9} / 1\right.$ vs. $\left.<50 \times 10^{9} / 1\right)$; risk (high vs. low + intermediate); ERG expression (low vs. high), BM blasts (more than or equal to the median vs. less than median), and BCR/ABL1 (presence vs. absence).

All calculations were performed using the SPSS 17.0 software package (SPSS Inc., Chicago, IL, USA), and $\mathrm{P}<0.05$ was considered to indicate a statistically significant difference.

\section{Results}

Expression of ERG in childhood ALL patients and control samples. ERG mRNA expression was retrospectively analyzed in pretreatment BM samples of 119 patients with newly diagnosed ALL and BM samples of 36 controls. ALL patients demonstrated higher ERG expression compared with controls $(\mathrm{P}<0.0001$; Fig. 1).

ERG expression and correlation to clinical features and molecular features. The clinical characteristics of 119 patients included in the present study are summarized in Table I. Overall, patients with low ERG expression exhibited higher pretreatment WBC counts (median, $32.2 \times 10^{9} / 1$ vs. $17.95 \times 10^{9} / 1 ; \mathrm{P}=0.011$ ), compared with the high ERG expression group. In addition, 
Table I. Clinical characteristics of patients with high and low ERG expression.

\begin{tabular}{|c|c|c|c|}
\hline Characteristic & Low ERG $(\mathrm{n}=59)$ & High ERG $(n=60)$ & P-value \\
\hline Age, years & & & 0.432 \\
\hline Median & 7.5 & 5 & \\
\hline Range & $1-14$ & $1-14$ & \\
\hline Sex, male, n $(\%)$ & $35(59)$ & $41(68)$ & 0.306 \\
\hline WBC count, $\times 10^{9} / 1$ & & & 0.011 \\
\hline Median & 32.20 & 17.95 & \\
\hline Range & $2.4-552.9$ & $0.8-760.0$ & \\
\hline PLT count, $\times 10^{9} / 1$ & & & 0.139 \\
\hline Median & 48 & 58 & \\
\hline Range & $10-330$ & $4-359$ & \\
\hline BM blasts, $\%$ & & & 0.912 \\
\hline Median & 90 & 90 & \\
\hline Range & $61-98$ & $61-98$ & \\
\hline PB blasts, $\%$ & & & 0.105 \\
\hline Median & 30 & 14.5 & \\
\hline Range & $0-85$ & $0-80$ & \\
\hline Extramedullary involvement, n (\%) & & & 0.623 \\
\hline Yes & $1(2)$ & $3(5)$ & \\
\hline Immunophenotype, n (\%) & & & 0.027 \\
\hline B-ALL & $40(68)$ & $51(85)$ & \\
\hline T-ALL & $19(32)$ & $9(15)$ & \\
\hline Risk, n (\%) & & & 0.117 \\
\hline Low & $13(22)$ & $22(37)$ & \\
\hline Intermediate & $15(25)$ & $13(22)$ & \\
\hline High & $31(53)$ & $25(41)$ & \\
\hline Ik6, n (\%) & & & 0.396 \\
\hline Mutated & $5(8)$ & $8(13)$ & \\
\hline Unmuated & $54(92)$ & $52(87)$ & \\
\hline BCR/ABL1, n (\%) & & & 0.774 \\
\hline Presence & $5(8)$ & $6(10)$ & \\
\hline Absence & $54(92)$ & $54(90)$ & \\
\hline MLL/AF4, n (\%) & & & 1.000 \\
\hline Presence & $1(2)$ & $1(2)$ & \\
\hline Absence & $58(98)$ & $59(98)$ & \\
\hline Day 22 MRD, n (\%) & & & 0.888 \\
\hline$\geq 0.01 \%$ & $7(12)$ & $6(10)$ & \\
\hline$<0.01 \%$ & $52(88)$ & $54(90)$ & \\
\hline
\end{tabular}

ERG, ETS-related gene; WBC, white blood cell; BM, bone marrow; PB, peripheral blood; PLT, platelet; ALL, acute lymphoblastic leukemia; Ik6, Ikaros isoform 6; BCR/ABL1, breakpoint cluster region/Abelson murine leukemia viral oncogene homolog 1; MRD, minimal residual disease.

low expression of ERG was associated with higher percentage of T-ALL ( $\mathrm{P}=0.027)$. However, there was no significant association between the ERG expression levels and the age, gender, platelet count, BM blasts, peripheral blood blasts extramedullary involvement, the risk group, Ik6 mutation, presence of BCR/ABL1 or MLL/AF4, and day 22 minimal residual disease.

In the subgroup analysis regarding the association between ERG expression values and molecular genetics, no significant difference was observed between patients with BCR/ABL1 compared with those patients without this fusion gene $(P=0.273)$. Similarly, there was no significant difference in ERG expression levels between IK6 positive and negative groups $(\mathrm{P}=0.262)$.

Outcome and survival in childhood ALL patients with respect to ERG expression. Compared with high ERG expressing 
Table II. Outcomes according to ERG expression.

\begin{tabular}{lccc}
\hline Outcome & Low ERG & High ERG & P-value \\
\hline $\begin{array}{l}\text { Induction regimen } \\
\quad \text { Sensitive (\%) }\end{array}$ & $44(79)$ & $53(91)$ & \\
CR & & & 1.000 \\
$\quad$ No (\%) & $3(5.4)$ & $6(6.6)$ & \\
Relapse & & & 0.009 \\
$\quad$ Yes (\%) & $18(33)$ & $7(12)$ & \\
Relapse free survival & & & 0.036 \\
$\quad$ Median, months & 62.5 & 64 & \\
Relapse-free at 5-year, \% & 58 & 79 & \\
$\quad$ 95\% CI & $44-72$ & $68-89$ & \\
Overall survival & & & 0.620 \\
$\quad$ Median, months & 71 & 65 & \\
Alive at 5-year, \% & 71 & 78 & \\
95\% CI & $58-83$ & $67-89$ & \\
\hline
\end{tabular}

ERG, ETS-related gene; CI, confidence interval; CR, complete remission.

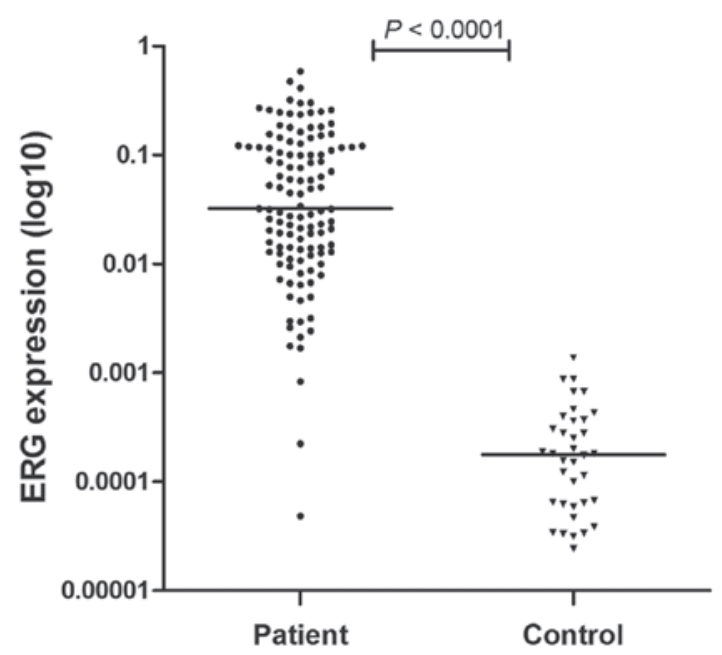

Figure 1. ERG expression levels in 119 pediatric ALL patients and 36 controls. An independent samples t-test was used for the comparisons of ERG expression levels between two groups, using the $2^{\mu(\Delta C T)}$ values as ERG quantitative expression levels. The line indicates the median value. ERG expression levels demonstrated a significant difference between childhood ALL patients and controls $(\mathrm{P}<0.0001)$. ERG, ETS-related gene; ALL, acute lymphoblastic leukemia.

patients, patients with low ERG expression had a higher relapse rate ( 33 vs. $12 \%$; $\mathrm{P}=0.009$; Table II). Patients with low ERG expression exhibited a reduced prednisone response (79 vs. $91 \%$; $\mathrm{P}=0.055$; Table II). However, no statistical significance was observed in CR rates between the low ERG group and high ERG group.

The median follow-up time was 67.5 months with a range of 1-93 months. Following the exclusion of 9 patients who received hematopoietic stem cell transplantation and 2 patients whose exact survival data could not be obtained, the remaining 108 ALL patients were included for analyses of overall OS and
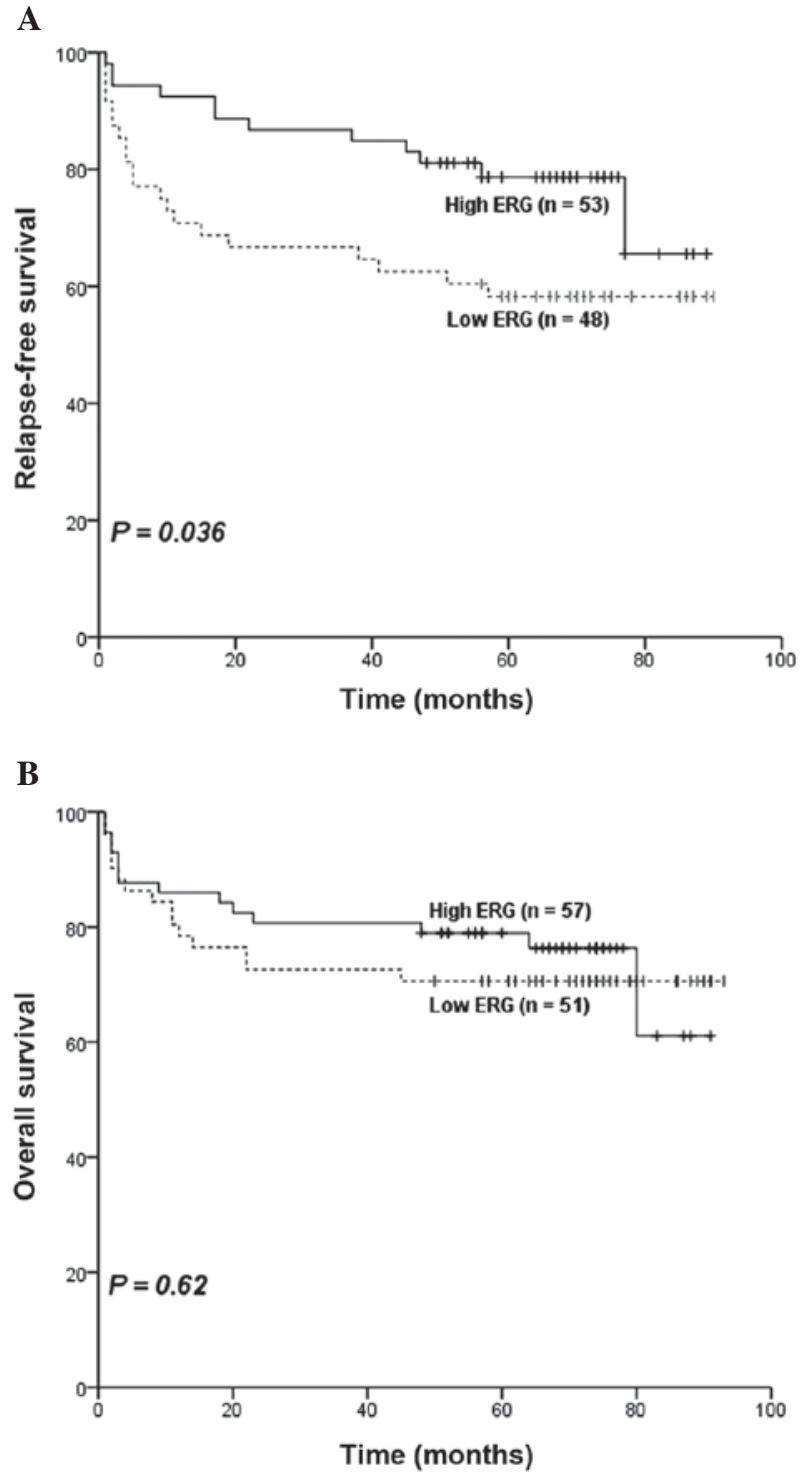

Figure 2. Influence of ERG expression on outcome in childhood acute lymphoblastic leukemia patients. (A) Patients with low ERG expression had inferior RFS ( $\mathrm{P}=0.036)$. Kaplan-Meier analysis demonstrated that estimated 5-year RFS rate for low ERG expressers was 58\%, whereas the estimated 5 -year OS rate for high ERG expressers was 79\%. (B) No significant difference in OS was observed between the high and low ERG groups $(\mathrm{B})(\mathrm{P}=0.62)$. ERG, ETS-related gene; RFS, relapse-free survival; OS, overall survival.

101 for RFS. RFS was significantly different between the two groups ( $\mathrm{P}=0.036$; Fig. 2A), patients in high $\mathrm{ERG}$ group had an estimated 5-year relapse-free rate of 79\% (95\% CI, 68-89\%; Table II) compared with 58\% (95\% CI, 44-72\%; Table II) in the low ERG group. Furthermore, the estimated 5-year survival rate was $71 \%$ (95\% CI, 58-83\%; Table II) in the low ERG group compared with 78\% (95\% CI, 67-89\%; Table II) in the high ERG group, however, no statistical difference was observed for differences in OS between the two groups ( $\mathrm{P}=0.62$; Fig. 2B).

Considering the difference of therapy in LR, IR and HR patients, survival analyses for OS and RFS based on ERG expression were also conducted in the LR, IR and HR subgroups respectively. However, the results did not indicate any survival difference between the high ERG group and the low ERG group (data not shown) in any subgroup. 
Table III. Multivariate analyses for RFS and OS in pediatric ALL patients.

\begin{tabular}{|c|c|c|c|c|c|c|}
\hline \multirow[b]{2}{*}{ Factor } & \multicolumn{3}{|c|}{ RFS } & \multicolumn{3}{|c|}{ OS } \\
\hline & HR & $95 \% \mathrm{CI}$ & P-value & HR & $95 \% \mathrm{CI}$ & P-value \\
\hline Age, $\leq 1$ year, $\geq 10$ years vs. $1-10$ years & 1.67 & $0.82-3.42$ & 0.157 & 1.83 & $0.87-3.84$ & 0.109 \\
\hline $\mathrm{WBC}, \geq 50 \times 10^{9} / 1$ vs. $<50 \times 10^{9} / 1$ & 1.75 & $0.86-3.59$ & 0.125 & 2.19 & $1.05-4.57$ & 0.036 \\
\hline Risk, high vs. low + intermediate & 1.77 & $0.88-3.55$ & 0.108 & 1.72 & $0.83-3.59$ & 0.146 \\
\hline ERG expression, low vs. high & 2.17 & $1.05-4.48$ & 0.036 & 1.21 & $0.58-2.50$ & 0.624 \\
\hline BM blast $\%, \geq$ median vs. $<$ median & 2.47 & $1.13-5.38$ & 0.023 & 2.87 & $1.22-6.73$ & 0.015 \\
\hline BCR/ABL1, presence vs. absence & 3.41 & $1.38-8.42$ & 0.008 & 2.19 & $0.82-5.88$ & 0.119 \\
\hline
\end{tabular}

ALL, acute lymphoblastic leukemia; OS, overall survival; RFS, relapse-free survival; ERG, ETS-related gene; WBC, white blood cell; BM, bone marrow; BCR/ABL1, breakpoint cluster region/Abelson murine leukemia viral oncogene homolog 1; HR, hazard ratio; CI, confidence interval.

Table IV. ERG expression in childhood B-ALL patients.

\begin{tabular}{|c|c|c|c|}
\hline Characteristic & $\begin{array}{c}\text { Low ERG } \\
\qquad(\mathrm{n}=40)\end{array}$ & $\begin{array}{l}\text { High ERG } \\
\quad(n=51)\end{array}$ & P-value \\
\hline WBC count, $\mathrm{x} 10^{9} / 1$ & & & 0.037 \\
\hline Median & 23.6 & 12.7 & \\
\hline Range & $2.4-552.9$ & $0.8-760$ & \\
\hline \multicolumn{4}{|l|}{ Outcome } \\
\hline Response to prednisone & & & 0.155 \\
\hline Sensitive, n (\%) & $29(79)$ & $43(90)$ & \\
\hline $\mathrm{CR}$ & & & 1.000 \\
\hline No, n $(\%)$ & $2(5.4)$ & $4(7.2)$ & \\
\hline Relapse & & & 0.029 \\
\hline Yes, n (\%) & $12(32)$ & $6(13)$ & \\
\hline Relapse free survival & & & 0.038 \\
\hline Relapse-free at 5-year, $\%$ & 54 & 77 & \\
\hline $95 \% \mathrm{CI}$ & $38-71$ & $64-89$ & \\
\hline Overall survival & & & 0.628 \\
\hline Alive at 5-year, $\%$ & 68 & 78 & \\
\hline $95 \% \mathrm{CI}$ & $53-83$ & $66-89$ & \\
\hline
\end{tabular}

B-ALL, B cell acute lymphoblastic leukemia; ERG, ETS-related gene; WBC, white blood cell; CI, confidence interval; CR, complete remission.

Multivariate analysis for clinical outcome in childhood ALL. A multivariate analysis including ERG expression, age, WBC counts, risk, BM blast and BCR/ABL1 was also performed to determine the prognostic importance of ERG expression on RFS and OS. Subsequent to adjusting for the impact of other factors, ERG expression remained an independent prognostic factor for RFS (Table III). In the Cox proportional hazards model, BM blast (more than or equal to the median vs. less than the median) and BCR/ABL1 (presence vs. absence) were independent prognostic factors for RFS (Table III). In addition, WBC counts
A

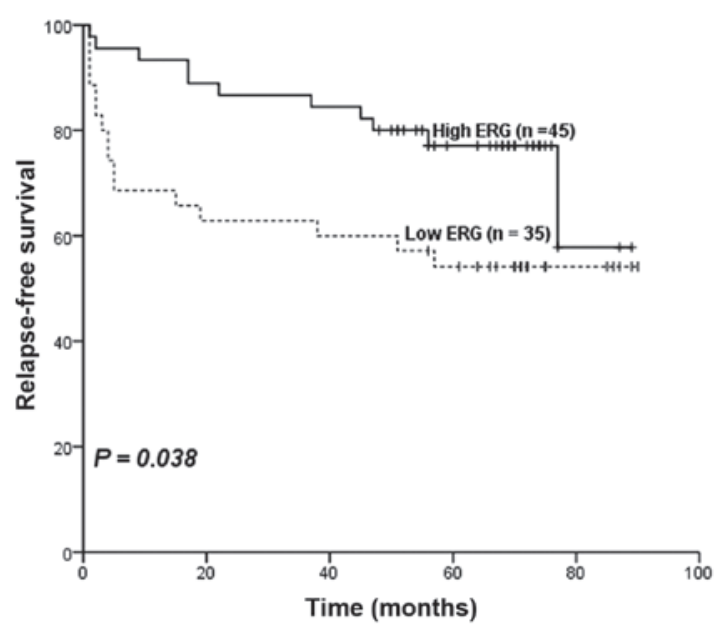

B

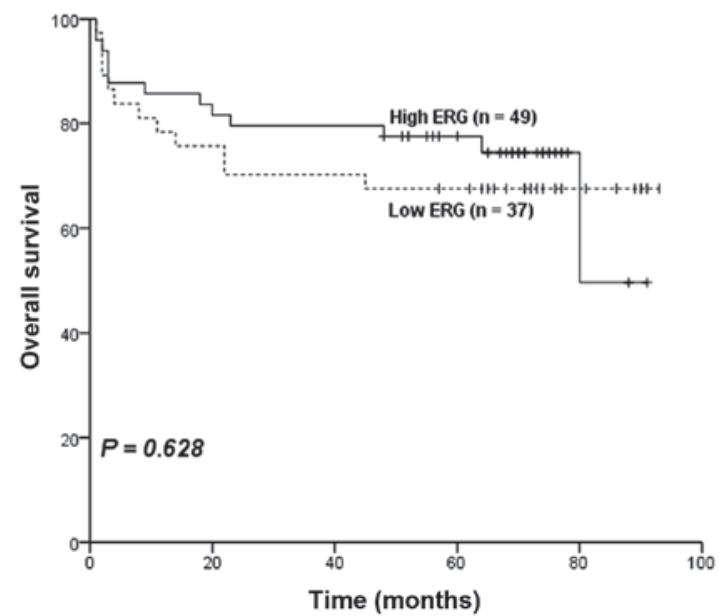

Figure 3. Influence of ERG expression on outcome in childhood B-ALL patients. (A) A significance difference in relapse-free survival was observed between the low ERG group and high ERG group (54 vs. 77\%; $\mathrm{P}=0.038$ ). (B) No significant difference in overall survival was identified between the high and low ERG groups in $\mathrm{B}-\mathrm{ALL}$ patients $(\mathrm{P}=0.628)$. ERG, ETS-related gene; B-ALL, B cell acute lymphoblastic leukemia.

$\left(\geq 50 \times 10^{9} / 1\right.$ vs. $\left.<50 \times 10^{9} / 1\right)$ and $\mathrm{BM}$ blast (more than or equal to the median vs. less than the median), were independent prognostic factors for OS (Table III). 
Table V. Multivariate analyses for RFS and OS in pediatric B-ALL patients.

\begin{tabular}{|c|c|c|c|c|c|c|}
\hline \multirow[b]{2}{*}{ Factor } & \multicolumn{3}{|c|}{ RFS } & \multicolumn{3}{|c|}{ OS } \\
\hline & HR & $95 \% \mathrm{CI}$ & P-value & HR & $95 \% \mathrm{CI}$ & P-value \\
\hline Age, $\leq 1$ year, $\geq 10$ years vs. $1-10$ years & 2.41 & $1.1-5.26$ & 0.028 & 2.79 & $1.25-6.20$ & 0.012 \\
\hline WBC, $\geq 50 \times 10^{9} / 1$ vs. $<50 \times 10^{9} / 1$ & 2.77 & $1.25-6.17$ & 0.013 & 2.87 & $1.29-6.37$ & 0.010 \\
\hline Risk, high vs. low + intermediate & 1.64 & $0.61-4.36$ & 0.286 & 1.31 & $0.49-3.50$ & 0.353 \\
\hline ERG expression, low vs. high & 1.85 & $0.83-4.16$ & 0.153 & 1.21 & $0.55-2.68$ & 0.632 \\
\hline BM blast $\%, \geq$ median vs. $<$ median & 2.16 & $0.79-5.90$ & 0.112 & 2.47 & $0.83-7.36$ & 0.078 \\
\hline $\mathrm{BCR} / \mathrm{ABL}$, presence vs. absence & 4.60 & $1.76-12.02$ & 0.002 & 1.98 & $0.67-5.80$ & 0.098 \\
\hline
\end{tabular}

B-ALL, B-cell acute lymphoblastic leukemia; BM, bone marrow; CI, confidence interval; CR, complete remission; ERG, ETS-related gene; HR, hazard ratio; WBC, white blood cell; OS, overall survival; RFS, relapse free survival; BCR/ABL1, breakpoint cluster region/Abelson murine leukemia viral oncogene homolog 1.

ERG expression in childhood B-ALL patients. ERG expression levels were also analyzed in $91 \mathrm{~B}-\mathrm{ALL}$ patients. Among all the clinical features described above, there was only a significant difference in WBC counts between the low ERG group and the high ERG group (median in the low ERG group, $23.6 \times 10^{9} / 1$ vs. median in the high ERG group, 12.7x 10\%/1; P=0.037) (Table IV). Subsequently, the relevance between ERG expression levels and outcomes in B-ALL patients was investigated. Patients with low ERG expression had higher relapse rate ( 32 vs. $13 \%$; $\mathrm{P}=0.029$; Table IV). No significant difference was observed in CR rates $(\mathrm{P}=1.000)$ and prednisone response $(\mathrm{P}=0.155)$ between the two groups based on ERG expression. Furthermore, survival analyses suggested that patents with low ERG expression had inferior RFS $(\mathrm{P}=0.038$; estimated 5-year relapse-free rate, 54 vs. 77\%; Table IV and Fig. 3A). However, no significant difference was observed in OS $(\mathrm{P}=0.628$; estimated 5 -year survival rate, $68 \%$ vs. $78 \%$; Table IV and Fig. 3B) was observed between patients with high ERG expression and those with low ERG expression. Results from multivariate analysis indicated that in childhood B-ALL patients, ERG was not an independent prognostic factor, for either OS, or for RFS. The independent prognostic factors for OS were age ( $\leq 1$ year, $\geq 10$ years vs. $1-10$ years) and WBC counts $\left(\geq 50 \times 10^{9} / 1\right.$ vs. $<50 \times 10^{9} / 1$; Table V). In addition, age ( $\leq 1$ year, $\geq 10$ years vs. $1-10$ years), WBC counts $\left(\geq 50 \times 10^{9} / 1 \mathrm{vs} .<50 \times 10^{9} / 1\right)$ and BCR/ABL1 (presence vs. absence) were independent prognostic factors for RFS (Table V).

\section{Discussion}

Treatment improvement in ALL requires an optimal risk stratification of patients to guide subsequent risk-adapted treatment. Thus, molecular study of ALL has always been one of the most active areas of leukemia research. In the present study, the ERG expression levels in a cohort of 119 childhood ALL patients and its correlation to clinical features and outcome were investigated. The results of the current study support that ERG expression has an association with the outcome of childhood ALL patients.
Together with its $>30$ ETS family members, ERG acts as downstream nuclear targets of signal transduction pathways regulating and promoting cell differentiation, proliferation, and tissue invasion $(5,7,23)$. ERG rearrangements with EWS RNA binding protein 1 and FUS RNA binding protein have been respectively identified in Ewing sarcomas harboring $\mathrm{t}(21 ; 22)$ (q22;q12) and in AML with $\mathrm{t}(16 ; 21)$ (p11;q22) $(8,24)$, and are likely to increase the oncogenic activity of the resulting chimeric transcription factors by redirecting them to specific targets (10).

Furthermore, in hematopoietic tissues, ERG expression is restricted to progenitor cells (25). High expression of ERG is significantly correlated with the immature subtypes of AML (10). The present study compared BM samples from childhood ALL patients with those of controls, and ERG overexpression was observed in pediatric ALL patients with more immature leukemia cells in their bone marrow. The above results suggest that ERG may be associated with the outcomes of pediatric ALL patients.

BCR/ABL1 positivity is a particularly poor prognostic marker for ALL (26-28). In addition, dominant-negative Ikaros isoform, notably Ik6, has been reported to be highly expressed in ALL, and correlated with clinical outcome (29). The relevance between ERG expression and the presence of BCR/ABL1 or IK6 mutations in pediatric ALL required further elucidation. The present study analyzed ERG expression values in patients according to BCR/ABL1 and IK6 mutation status. The results demonstrated that there was no significant difference in ERG expression levels between patients with BCR/ABL1 or IK6 and those without these genetic abnormities.

The current study demonstrated that patients in the low ERG group demonstrated a significantly inferior outcome compared with the high ERG group. Low ERG expression identified a group of patients with higher WBC counts and higher percentages of T-ALL, which have been treated as clinically poor prognostic factors in childhood ALL. In addition, low ERG expression conferred an impact on relapse rate and a significant influence on RFS was suggested. In multivariate analysis, subsequent to adjusting for the impact of other factors, ERG remained an independent prognostic factor for RFS. Furthermore, in childhood B-ALL patients, low ERG 
expression was associated with higher WBC counts, higher relapse rate and poor RFS. The conclusions on how ERG expression levels affect patient outcome and survival between the pediatric group in the present study and other adult groups are inconsistent. As there is no previous study available regarding ERG expression on pediatric ALL, the possible explanations for this discrepancy are as follows: i) Compared with other studies focused on adult leukemia and childhood AML, the current study included patients from a childhood ALL population with marked differences in biology, etiology, treatment protocol and outcome in their diseases; and ii) ERG expression level has been reported to correlate with other genes, such as meningioma (disrupted in balanced translocation) 1 and brain and acute leukemia, cytoplasmic (14), which may also influence the prognostic role of ERG (30), thus, there may be other genes cooperating with or acting against ERG that directly affect its influence on survival in childhood ALL patients; iii) in addition, the inconsistent conclusions may be a result of unadjusted study design confounder from different research centers, including different diseases, ethnic background, medical resources and treatment protocols.

To the best of our knowledge, this is the first study to focus on ERG expression in pediatric ALL patients. However, certain shortcomings remain, including that a relatively small sample size may not be enough to draw a definitive conclusion, and the retrospective nature of the present study may present a certain bias.

In conclusion, the present study suggests that ERG expression level may be useful as a prognostic factor for pediatric ALL stratification, however, further large-scale and well-designed prospective studies are required.

\section{Acknowledgements}

The present study was supported by grants from the National Natural Science Foundation of China (grant nos. 30971283, 81170502, 81470304, 81200386 and 81300400), the Zhejiang Provincial Natural Science Foundation of China (grant nos. LZ12H08001 and Q12H080008), the Department of Health of Zhejiang Province of China (grant no. 2013KYA107) and the Leukemia Research Innovative Team of Zhejiang Province (grant no. 2011R50015).

\section{References}

1. Harvey RC, Mullighan CG, Wang X, Dobbin KK, Davidson GS, Bedrick EJ, Chen IM, Atlas SR, Kang H, Ar K, et al: Identification of novel cluster groups in pediatric high-risk B-precursor acute lymphoblastic leukemia with gene expression profiling: Correlation with genome-wide DNA copy number alterations, clinical characteristics, and outcome. Blood 116: 4874-4884, 2010.

2. Bailey LC, Lange BJ, Rheingold SR and Bunin NJ: Bone-marrow relapse in paediatric acute lymphoblastic leukaemia. Lancet Oncol 9: 873-883, 2008.

3. Moorman AV, Ensor HM, Richards SM, Chilton L, Schwab C, Kinsey SE, Vora A, Mitchell CD and Harrison CJ: Prognostic effect of chromosomal abnormalities in childhood B-cell precursor acute lymphoblastic leukaemia: Results from the UK Medical Research Council ALL97/99 randomised trial. Lancet Oncol 11: 429-438, 2010.

4. Moorman AV: The clinical relevance of chromosomal and genomic abnormalities in B-cell precursor acute lymphoblastic leukaemia. Blood Rev 26: 123-135, 2012.

5. Oikawa T: ETS transcription factors: possible targets for cancer therapy. Cancer Sci 95: 626-633, 2004.
6. Anderson MK, Hernandez-Hoyos G, Diamond RA and Rothenberg EV: Precise developmental regulation of Ets family transcription factors during specification and commitment to the T cell lineage. Development 126: 3131-3148, 1999.

7. Hart AH, Corrick CM, Tymms MJ, Hertzog PJ and Kola I: Human ERG is a proto-oncogene with mitogenic and transforming activity. Oncogene 10: 1423-1430, 1995.

8. Sorensen PH, Lessnick SL, Lopez-Terrada D, Liu XF, Triche TJ and Denny CT: A second Ewing's sarcoma translocation, $\mathrm{t}(21 ; 22)$, fuses the EWS gene to another ETS-family transcription factor, ERG. Nat Genet 6: 146-151, 1994.

9. Tomlins SA, Rhodes DR, Perner S, Dhanasekaran SM, Mehra R, Sun XW, Varambally S, Cao X, Tchinda J, Kuefer R, et al: Recurrent fusion of TMPRSS2 and ETS transcription factor genes in prostate cancer. Science 310: 644-648, 2005.

10. Marcucci G, Baldus CD, Ruppert AS, Radmacher MD, Mrózek K, Whitman SP, Kolitz JE, Edwards CG, Vardiman JW, Powell BL, et al: Overexpression of the ETS-related gene, ERG, predicts a worse outcome in acute myeloid leukemia with normal karyotype: A Cancer and Leukemia Group B study. J Clin Oncol 23: 9234-9242, 2005.

11. Marcucci G, Maharry K, Whitman SP, Vukosavljevic T, Paschka P, Langer C, Mrózek K, Baldus CD, Carroll AJ, Powell BL, et al: High expression levels of the ETS-related gene, ERG, predict adverse outcome and improve molecular risk-based classification of cytogenetically normal acute myeloid leukemia: A Cancer and Leukemia Group B Study. J Clin Oncol 25: 3337-3343, 2007.

12. Eid MA, Attia M, Abdou S, El-Shazly SF, Elahwal L, Farrag W and Mahmoud L: BAALC and ERG expression in acute myeloid leukemia with normal karyotype: Impact on prognosis. Int J Lab Hematol 32: 197-205, 2010.

13. Metzeler KH, Dufour A, Benthaus T, Hummel M, Sauerland MC, Heinecke A, Berdel WE, Büchner T, Wörmann B, Mansmann U,et al: ERG expression is an independent prognostic factor and allows refined risk stratification in cytogenetically normal acute myeloid leukemia: A comprehensive analysis of ERG, MN1, and BAALC transcript levels using oligonucleotide microarrays. J Clin Oncol 27: 5031-5038, 2009.

14. Schwind S, Marcucci G, Maharry K, Radmacher MD, Mrózek K, Holland KB, Margeson D, Becker H, Whitman SP, Wu YZ, et al: BAALC and ERG expression levels are associated with outcome and distinct gene and microRNA expression profiles in older patients with de novo cytogenetically normal acute myeloid leukemia: A Cancer and Leukemia Group B study. Blood 116: 5660-5669, 2010

15. Baldus CD, Burmeister T, Martus P, Schwartz S, Gökbuget N, Bloomfield CD, Hoelzer D, Thiel E and Hofmann WK: High expression of the ETS transcription factor ERG predicts adverse outcome in acute T-lymphoblastic leukemia in adults. J Clin Oncol 24: 4714-4720, 2006.

16. Baldus CD, Martus P, Burmeister T, Schwartz S, Gökbuget N, Bloomfield CD, Hoelzer D, Thiel E and Hofmann WK: Low ERG and BAALC expression identifies a new subgroup of adult acute T-lymphoblastic leukemia with a highly favorable outcome. J Clin Oncol 25: 3739-3745, 2007.

17. Pigazzi M, Masetti R, Martinolli F, Manara E, Beghin A, Rondelli R, Locatelli F, Fagioli F, Pession A and Basso G: Presence of high-ERG expression is an independent unfavorable prognostic marker in MLL-rearranged childhood myeloid leukemia. Blood 119: 1086-1087; author reply 1087-1088, 2012.

18. Hermkens MC, van den Heuvel-Eibrink MM, Arentsen-Peters ST, Baruchel A, Stary J, Reinhardt D, Zimmerman M, de Haas V, Pieters R and Zwaan CM: The clinical relevance of BAALC and ERG expression levels in pediatric AML. Leukemia 27: 735-737, 2013.

19. Subspecialty Group of Hematology Diseases, The Society of Pediatrics, Chinese Medical Association; Editorial Board, Chinese Journal of Pediatrics: Recommendations for diagnosis and treatment of acute lymphoblastic leukemia in childhood (3rd revised version). Zhonghua Er Ke Za Zhi 44: 392-395, 2006 (In Chinese).

20. Xu XJ, Tang YM, Shen HQ, Song H, Yang SL, Shi SW and $\mathrm{Xu}$ WQ: Day 22 of induction therapy is important for minimal residual disease assessment by flow cytometry in childhood acute lymphoblastic leukemia. Leuk Res 36: 1022-1027, 2012.

21. Mu Q, Wang Y, Chen B, Qian W, Meng H, Tong H, Chen F, Ma Q, $\mathrm{Ni}$ W, Chen S and Jin J: High expression of Musashi-2 indicates poor prognosis in adult B-cell acute lymphoblastic leukemia. Leuk Res 37: 922-927, 2013. 
22. Mullighan CG, Miller CB, Radtke I, Phillips LA, Dalton J, Ma J, White D, Hughes TP, Le Beau MM, Pui CH, et al: BCR-ABL1 lymphoblastic leukaemia is characterized by the deletion of Ikaros. Nature 453: 110-114, 2008

23. Oikawa T and Yamada T: Molecular biology of the Ets family of transcription factors. Gene 303: 11-34, 2003.

24. Ichikawa H, Shimizu K, Hayashi Y and Ohki M: An RNA-binding protein gene, TLS/FUS, is fused to ERG in human myeloid leukemia with $\mathrm{t}(16 ; 21)$ chromosomal translocation. Cancer Res 54: 2865-2868, 1994.

25. Rainis L, Toki T, Pimanda JE, Rosenthal E, Machol K, Strehl S, Göttgens B, Ito E and Izraeli S: The proto-oncogene ERG in megakaryoblastic leukemias. Cancer Res 65: 7596-7602, 2005.

26. Dombret H, Gabert J, Boiron JM, Rigal-Huguet F, Blaise D, Thomas X, Delannoy A, Buzyn A, Bilhou-Nabera C, Cayuela JM, et al: Outcome of treatment in adults with Philadelphia chromosome-positive acute lymphoblastic leukemia-results of the prospective multicenter LALA-94 trial. Blood 100: 2357-2366, 2002.
27. Gleissner B, Gökbuget N, Bartram CR, Janssen B, Rieder H, Janssen JW, Fonatsch C, Heyll A, Voliotis D, Beck J, et al: Leading prognostic relevance of the BCR-ABL translocation in adult acute B-lineage lymphoblastic leukemia: A prospective study of the German Multicenter Trial Group and confirmed polymerase chain reaction analysis. Blood 99: 1536-1543, 2002.

28. Mancini M, Scappaticci D, Cimino G, Nanni M, Derme V, Elia L, Tafuri A, Vignetti M, Vitale A, Cuneo A, et al: A comprehensive genetic classification of adult acute lymphoblastic leukemia (ALL): Analysis of the GIMEMA 0496 protocol. Blood 105: 3434-3441, 2005

29. Liu P, Lin Z, Qian S, Qiao C, Qiu H, Wu Y, Li J and Ge Z: Expression of dominant-negative Ikaros isoforms and associated genetic alterations in Chinese adult patients with leukemia. Ann Hematol 91: 1039-1049, 2012

30. Staffas A, Kanduri M, Hovland R, Rosenquist R, Ommen HB, Abrahamsson J, Forestier E, Jahnukainen K, Jónsson ÓG, Zeller B, et al: Presence of FLT3-ITD and high BAALC expression are independent prognostic markers in childhood acute myeloid leukemia. Blood 118: 5905-5913, 2011. 